\title{
Philosophiques
}

\section{Livres reçus (printemps 2001)}

Volume 28, numéro 1, printemps 2001

La nature des normes

URI : https://id.erudit.org/iderudit/004951ar

DOI : https://doi.org/10.7202/004951ar

Aller au sommaire du numéro

Éditeur(s)

Société de philosophie du Québec

ISSN

0316-2923 (imprimé)

1492-1391 (numérique)

Découvrir la revue

Citer ce document

(2001). Livres reçus (printemps 2001). Philosophiques, 28(1), 243-245.

https://doi.org/10.7202/004951ar

Ce document est protégé par la loi sur le droit d'auteur. L'utilisation des services d'Érudit (y compris la reproduction) est assujettie à sa politique d'utilisation que vous pouvez consulter en ligne.

https://apropos.erudit.org/fr/usagers/politique-dutilisation/
Cet article est diffusé et préservé par Érudit.

Érudit est un consortium interuniversitaire sans but lucratif composé de l'Université de Montréal, l'Université Laval et l'Université du Québec à Montréal. Il a pour mission la promotion et la valorisation de la recherche. https://www.erudit.org/fr/ 


\section{Livres reçus (printemps 2001)}

Barberousse, Anouk, La physique face à la probabilité, Paris, Vrin ( "Mathesis »), 2000, 210 pages.

Barck, Karlheinz, Martin Fontius, Dieter Schlensdedt, Burkhart Steinwachs et Friedrich Wolfzettel (sous la direction de), Ästhetische Grundbegriffe (Historisches Wörterbuch in sieben Bänden. Band 1: Absenz bis Darstellung), Stuttgart/Weimar, Verlag J.B. Metzler, 2000, 875 pages.

Bégout, Bruce, La généalogie de la logique. Husserl, l'antéprédicatif et le catégorial, Paris, Vrin ( "Histoire de la philosophie »), 379 pages.

Berlioz, Dominique, Berkeley. Un nominalisme réaliste, Paris, Vrin («Bibliothèque des philosophies »), 2000, 220 pages.

Boehm, Rudolph, Critique des fondements de l'époque, traduit de l'allemand par Benoît-Thadée Standaert, Paris-Montréal, L'Harmattan 2000, 317 pages.

Boyer, Alain, Hors du temps. Un essai sur Kant, Paris, Vrin ("Problèmes et controverses »), 2001.

Counet, Jean-Michel, Mathématiques et dialectique chez Nicolas de Cuse, Paris, Vrin, ( Études de philosophie médiévale »), 2000, 456 pages.

Duchesneau, François, Guy Lafrance et Claude Piché (sous la direction de), Kant actuel. Hommage à Pierre Laberge, Montréal/ Paris, Bellarmin/ Vrin ( Analytiques »), 2000, 303 pages.

Dumont, Fernand, Un témoin de l'homme, Entretiens colligés et présentés par Serge Cantin, Montréal, Éditions de l'Hexagone, 2000, 356 pages.

Élissalde, Yvan, Critique de l'interprétation, Paris, Vrin, ("Philologie et Mercure »), 2000, 306 pages.

Engel, Pascal (dir.), Précis de philosophie analytique, Paris, PUF («Thémis »), 2000, 359 pages.

Fisette, Denis et Pierre Poirier, Philosophie de l'esprit. État des lieux, Paris, Vrin ( "Pour demain »), 2000, 338 pages.

Frogneux, Nathalie, Hans Jonas ou la vie dans le monde, Bruxelles, Éditions De Boeck Université, 2001.

Goddard, Jean-Christophe, Fichte. Le moi et la liberté, Paris, PUF ( "Débats philosophiques »), 2000, 166 pages.

Gourinat, Jean-Baptiste, La dialectique des Stö̈ciens, Paris, Vrin, ( Histoire des doctrines de l'Antiquité classique »), 2000, 386 pages.

Hagenbruger, Ruth, Nutzen und Allgemeinheit. Überlegungen zu grundlegenden Prinzipien der praktischen Philosophie, Sankt Augustin, Academia-Verlag, 2000, 304 pages.

Henry, Michel, Incarnation. Une philosophie de la chair, Paris, Seuil, 2000, 374 pages.

PHILOSOPHIQUES 27/2 - Automne 2000, p. 243-245 
Hurka, Thomas, Virtue, Vice, and Value, Oxford, Oxford University Press, 2001, 272 pages.

Jaffo, Laurent (coord.), Le sens moral. Une histoire de la philosophie morale de Locke à Kant, Paris, PUF (« Débats philosophiques »), 2000, 140 pages.

Jonas, Hans, Le phénomène de la vie. Vers une biologie philosophique. Traduit de l'anglais par Danielle Lories. Bruxelles, De Boeck Université, 2001, 390 pages.

Lepage, François et Serge Lapierre, Logique partielle et savoir. Essai de philosophie formelle, Montréal/ Paris, Bellarmin/ Vrin ( Analytiques»), 2000, 265 pages.

Létourneau, Alain, L’herméneutique de Maurice Blondel, son émergence pendant la crise moderniste, Montréal, Bellarmin, 1998, 306 pages.

Malherbe, Jean-François, Le nomade polyglotte. L'excellence éthique en postmodernité, Montréal, Bellarmin, 2000, 225 pages.

Pender, E.E., Images of Persons Unseen. Plato's Metaphors for the Gods and the Soul, Sankt Augustin, Akademia Verlag ( International Plato Studies, Vol. 11), 2000, XII + 280 pages.

Saunders, Trevor J. et Luc Brisson, Bibliography on Plato's Laws. Revised and completed with an additionnal Bibliography on the Epinomis, Sankt Augustin, Akademia Verlag («International Plato Studies, Vol. $12 »), 2000,144$ pages.

Schelling, F.W.J., Exposition de mon système de la philosophie. - Sur le vrai concept de la philosophie de la nature, suivi de : Fichte, J.G., Sur l'exposition du système de l'identité de Schelling, traduits, présentés et annotés par Emmanuel Cattin, Paris, Vrin, 2000, 193 pages.

Seron, Denis, Introduction à la méthode phénoménologique, Bruxelles, Éditions De Boeck Université, 2000, 191 pages.

Talin, Christian, Anthropologie de l'animal de compagnie. L'animal, autre figure de l'altérité, Paris, L'Atelier de l'Archer ( Questions de temps »), 2000, 131 pages.

Tappolet, Christine, Émotions et valeurs, Paris, PUF («Philosophie morale »), 2000, 296 pages.

Thomas D'Aquin, Question disputée. L'union du verbe incarné (De unioni Verbi incarnati), traduction, introduction et notes par Marie-Hélène Deloffre, Paris, Vrin (« Textes philosophiques »), 2000, 256 pages.

Tully, James, Une étrange multiplicité. Le constitutionnalisme à une époque de diversité, traduit de l'anglais par Jude Des Chênes, Québec, Les Presses de l'Université Laval, 1999, 240 pages.

Zarka, Yves Charles, L'autre voie de la subjectivité, Paris, Beauchesne ( « Le grenier à sel »), 2000, 133 pages. 


\section{Livres reçus (automne 2000) $\cdot 245$}

Outre les ouvrages qui apparaissent dans cette liste, la rédaction de Philosophiques peut obtenir, pour fin de compte-rendu, la plupart des livres publiés récemment aux Presses Universitaires de France, chez Vrin, au Seuil et à L'Harmattan.

Les personnes désireuses de faire un compte rendu sont priées de s'adresser à :

Fabienne Pironet Université de Montréal Département de philosophie C.P. 6128 Succ. Centre-ville Montréal, Québec, H3C 3J7

Tél : (514) 343-7670

Télec : (514) 343-7899

Courriel : pironetf@philo.umontreal.ca 